\title{
Durability of Abstinence After Completing a Comprehensive Digital Smoking Cessation Program Incorporating a Mobile App, Breath Sensor, and Coaching: Cohort Study
}

Jennifer D Marler ${ }^{1}$, MD; Craig A Fujii ${ }^{1}$, BS, MIDS; Joseph A Galanko ${ }^{2}$, PhD; Daniel J Balbierz ${ }^{1}$, BS; David S Utley ${ }^{1}$, MD

\footnotetext{
${ }^{1}$ Carrot Inc., Redwood City, CA, United States

${ }^{2}$ Biostatistics Core for the Center for Gastrointestinal Biology and Disease and the Clinical Nutrition Research Center, Department of Medicine, Division of Gastroenterology and Hepatology, University of North Carolina at Chapel Hill, Chapel Hill, NC, United States
}

\author{
Corresponding Author: \\ Jennifer D Marler, MD \\ Carrot Inc. \\ 1400A Seaport Blvd \\ Suite 501 \\ Redwood City, CA, 94063 \\ United States \\ Phone: 14157577696 \\ Email: marler@carrot.co
}

\begin{abstract}
Background: Despite decreasing prevalence over the last several decades, cigarette smoking remains the leading cause of preventable death and disease, underscoring the need for innovative, effective solutions. Pivot is a novel, inclusive smoking cessation program designed for smokers along the entire spectrum of readiness to quit. Pivot leverages proven methods and technological advancements, including a personal portable breath carbon monoxide sensor, smartphone app, and in-app text-based coaching. We previously reported outcomes from the end of active Pivot program participation in 319 adult smokers. Herein, we report longer-term follow up in this cohort.
\end{abstract}

Objective: The aim of this study was to assess and report participant outcomes 3 months after completion of Pivot, including smoking behavior, quit rates, continuous abstinence rates and durability, and predictors of abstinence.

Methods: This prospective remote cohort study included US-based cigarette smokers aged 18 to 65 years who smoked $\geq 5$ cigarettes per day (CPD). Three months after completion of active participation in Pivot, final follow-up data were collected via an online questionnaire. Outcomes included smoking behavior (CPD and quit attempts), self-reported quit rates (7- and 30-day point prevalence abstinence [PPA]), and continuous abstinence rates (proportion who achieved uninterrupted abstinence) and duration. Exploratory regression analyses were performed to identify baseline characteristics associated with achievement of 7-day PPA, 30-day PPA, and continuous abstinence.

Results: A total of 319 participants completed onboarding (intention-to-treat [ITT]); 288/319 participants (90.3\%) completed follow up (completers) at a mean of 7.2 (SD 1.2) months after onboarding. At final follow up, CPD were reduced by 52.6\% (SE $2.1 ; P<.001)$ among all 319 participants, and most completers $(152 / 288,52.8 \%)$ reduced their CPD by at least 50\%. Overall, most completers $(232 / 288,80.6 \%)$ made at least one quit attempt. Quit rates increased after the end of Pivot; using ITT analyses, $35.4 \%$ (113/319) achieved 7-day PPA and 31.3\% (100/319) achieved 30-day PPA at final follow up compared with 32.0\% $(102 / 319)$ and $27.6 \%(88 / 319)$, respectively, at the end of the Pivot program. Continuous abstinence was achieved in about a quarter of those who onboarded $(76 / 319,23.8 \%)$ and in most who reported 30-day PPA at the end of Pivot $(76 / 88,86.4 \%)$, with a mean abstinence duration of 5.8 (SD 0.6) months. In exploratory regression analyses, lower baseline CPD, more positive baseline attitudes reflecting higher self-efficacy (higher confidence to quit and lower perceived difficulty of quitting), and higher education were associated with achieving abstinence.

Conclusions: This study provides the first longer-term outcomes of the Pivot smoking cessation program. At final follow up, quit rates increased and continuous abstinence was favorable; the majority who achieved abstinence at the end of Pivot sustained abstinence throughout follow up. Decreases in CPD persisted and most participants made a quit attempt. Overall, final follow-up 
outcomes were stable or improved when compared to previous outcomes from the end of the program. These findings validate earlier results, and suggest that Pivot is an effective and durable solution for smoking cessation.

Trial Registration: ClinicalTrials.gov NCT03295643; https://clinicaltrials.gov/ct2/show/NCT03295643

(J Med Internet Res 2021;23(2):e25578) doi: 10.2196/25578

\section{KEYWORDS}

smoking cessation; digital health; smartphone; digital sensor; carbon monoxide; breath sensor; biofeedback; mobile apps; health promotion; app

\section{Introduction}

\section{Background}

Tobacco use, primarily through cigarette smoking, is the leading cause of preventable disease, disability, and mortality in the United States [1]. Although smoking has declined over the last several decades, it remains a significant public health problem; in $2019,14.0 \%$ of US adults (34.1 million people) were still current cigarette smokers [2].

Quitting smoking is one of the most important steps one can take for their health and can add as much as a decade to life expectancy; accordingly, most smokers (approximately 70\%) want to quit $[3,4]$. Proven smoking cessation treatments include behavioral counseling and pharmacotherapy, which are now widely available. Use of these evidence-based approaches increases the rate of quitting by at least 40\% [5-8]. However, use remains low, with less than one-third of smokers using any proven cessation treatments (eg, behavioral counseling, medication). As a result, most quit attempts are unassisted and more than $90 \%$ of these attempts are unsuccessful [4].

With room to expand and improve treatment options, the last decade has seen novel approaches to smoking cessation, including mobile and web-based options. A 2019 meta-analysis by Whittaker et al [9] assessed phone text messaging and app-based interventions for smoking cessation. In an assessment comprising 13 studies with 14,133 participants, the authors reported that automated text messaging interventions were more effective than minimal smoking cessation support (relative risk [RR] 1.54, 95\% CI 1.19-2.00; $\mathrm{I}^{2}=71 \%$ ). The authors also assessed five studies comprising 3079 participants, comparing a smoking cessation smartphone app with lower-intensity smoking cessation support (either a lower-intensity app or nonapp minimal support). This assessment provided no evidence that smartphone apps improved the likelihood of smoking cessation (RR 1.00, 95\% CI 0.66-1.52; $\mathrm{I}^{2}=59 \%$ ), but the authors noted that the evaluated evidence was of very low certainty due to inconsistency and imprecision, highlighting the need for more randomized controlled trials (RCTs) in this area. More recently, Bricker et al [10] performed an RCT comparing an acceptance and commitment therapy-based smoking cessation smartphone app (iCanQuit, $\mathrm{n}=1214$ ) with a United States Clinical Practice Guideline (USCPG)-based app (QuitGuide, $n=1201$ ). At 12 months after randomization, iCanQuit participants had 1.49 times higher odds of quitting smoking compared with that of QuitGuide participants (28.2\%, 293/1040 vs 21.1\%, 225/1067; odds ratio [OR] $1.49,95 \%$ CI $1.22-1.83 ; P<.001)$.
The Pivot program is a novel digital health intervention for smoking cessation that seeks to expand on these previous findings with respect to both intervention design and associated outcomes. Pivot comprises a multiphase mobile app, as well as the first Food and Drug Administration (FDA)-cleared personal carbon monoxide (CO) breath sensor, and dedicated human coaching delivered through in-app text messaging. Pivot is designed for individuals with varying levels of readiness to quit, and is based on the USCPG for treating tobacco use and dependence.

A prospective cohort study evaluated outcomes in 319 adult smokers who underwent the Pivot program (intention to treat [ITT] cohort); $272(85.3 \%)$ participants completed the end-of-Pivot questionnaire (completer cohort) [11]. The study included individuals along the spectrum of readiness to quit; at study entry, the majority of participants $(66.5 \%, 212 / 319)$ were not planning on quitting smoking in the next 30 days. Participant engagement, changes in attitudes toward quitting smoking, and changes in smoking behavior during and at the end of the Pivot program (mean 4.1, SD 1.4 months after enrollment) were assessed. Participants had a mean of 12.4 (SD 7.1) weeks of active program engagement, defined as at least one of the following per week: completing a breath sample; logging a cigarette; starting or completing a daily activity, challenge, or check-in; or messaging one's coach. Repeated-measures linear mixed-model analyses demonstrated positive changes in attitudes at the end of the prequit portion of the program, with increased confidence to quit (4.2 to $7.4, P<.001)$ and decreased expected difficulty in maintaining quit ( 3.1 to $6.8, P<.001$ ). The quit attempt rate (ie, those making $\geq 1$ quit attempt lasting $\geq 1$ day) was $79.4 \%$ (216/272, completer analysis). At the end of Pivot, 7-day point prevalence abstinence (PPA) rates were $32.0 \%$ (102/319, ITT analysis) and 37.5\% (102/272, completer analysis); 30-day PPA rates were $27.6 \%$ (88/319, ITT) and $32.4 \%$ (88/272, completer). Moreover, 30-day PPA rates were comparable among those ready and not ready to quit in the next 30 days at baseline. Of those not achieving abstinence, $25.9 \%$ (44/170, completer) achieved $\geq 50 \%$ reduction in cigarettes per day (CPD) at the end of the Pivot program.

Although these data are encouraging, there is an ongoing need to assess the durability of short-term results, and thereby establish longer-term outcomes in novel smoking cessation programs such as Pivot.

\section{Objectives}

This report focuses on participant outcomes 3 months after the completion of Pivot, including smoking behavior, quit rates, 
continuous abstinence rates and durability, and predictors of abstinence.

\section{Methods}

\section{Study Design}

This was a prospective, open-label single-arm cohort study performed with institutional review board (IRB) approval. The study was performed remotely on an ambulatory basis. Study participants participated in the Pivot program and completed online study questionnaires. A detailed description of the study methodology was previously provided, with initial focus on outcomes at the end of active participation in Pivot [11].

\section{Consent and Ethical Approval}

All participants provided electronic informed consent before participation. The study was reviewed and approved by Solutions IRB (protocol number 2017/09/22) and was registered with Clinicaltrials.gov (NCT03295643).

\section{Pivot Program}

Pivot is a self-paced, comprehensive digital smoking cessation solution that includes an over-the-counter $\mathrm{CO}$ breath sensor, the multiphase Pivot mobile app, and human coaching delivered one-on-one through in-app text messaging [11].

Pivot Breath Sensor is a personal interactive FDA-cleared device that measures $\mathrm{CO}$ in exhaled breath. In line with wearable devices, the $\mathrm{CO}$ breath sensor provides real-time personal biometric data to users, enabling them to link their smoking behavior and $\mathrm{CO}$ values and track their progress in reducing or quitting smoking. This leverages the findings of several published studies [12-15] as well as expert opinion [16,17], which suggest that personal $\mathrm{CO}$ breath sample data can be educational and motivational, and may lead to changes in attitudes toward quitting and smoking behavior. To that end, the CO breath sensor is incorporated in the Pivot program as an engagement tool, with the intention that users will find their expired $\mathrm{CO}$ values informative and motivational.

In the multiphase Pivot app, participants could log cigarettes, follow trends in their $\mathrm{CO}$ values, complete educational and preparatory activities, set a quit date, make a quit plan, undertake short-term practice quits, learn about FDA-approved cessation medications, complete daily check-ins upon quitting smoking, and communicate with their coach.

Coaching was undertaken through asynchronous in-app text messaging, thus allowing participants to respond to coach-initiated contact or to initiate contact with their coach whenever it was convenient for them. Pivot coaches are trained specialists in tobacco cessation. The coach and Pivot participant are paired for the duration the participant is in Pivot to foster rapport and continuity. Coach-initiated contact included outreach 3 times a week from entry through the first 30 days after the quit date, once per week for the next 30 days, and then every other week for the last 30 days. Participants could initiate contact with their coach as frequently as desired.

The Pivot program's foundation is evidence-based and applies the USCPG-recommended "5 As" (Ask, Advise, Assess, Assist, and Arrange); tailors to one's readiness to quit smoking [18]; encourages the use of FDA-approved pharmacotherapy [18-21]; uses effective methods and supportive theories for smoking cessation (eg, motivational interviewing, cognitive behavioral therapy, and self-determination theory) [18,22-24]; and provides behavioral counseling through a live, dedicated coach $[6,18,21,25]$.

\section{Eligibility}

To be eligible for participation, individuals had to meet all of the following eligibility criteria: $18-65$ years of age, English-speaking, smoke $\geq 5 \mathrm{CPD}$, own and use a smartphone that is compatible with the Pivot app and breath sensor software (iPhone 5 and above, operating system iOS 9.0 and above, or Android operating system 4.4 and above), be employed for $\geq 20$ hours a week, and live in the United States. Although we aim for broad availability of Pivot through multiple channels such as private and public insurers, direct-to-consumer, and not-for-profit foundations, at the time this study was performed, Pivot was initially only available to individuals through their employers (self-insured employers or employee wellness programs). As such, the employment requirement was applied to assess Pivot in individuals closely aligned with Pivot's initial user population.

\section{Study Procedure}

Study participants completed an online screening form, a screening phone call, electronic informed consent, web registration, and the baseline electronic questionnaire. They were mailed the breath sensor, which they set up independently using the labeling. Technical support was available as needed. Participants were assigned a coach with whom they worked for the duration of their participation in Pivot. Over the entire study, participants were compensated US $\$ 10$ to $\$ 50$ per completed study questionnaire and US $\$ 50$ for returning the CO breath sensor for up to a total of US \$315, using Visa gift cards. Specifically, for this follow-up portion of the study, participants were compensated US $\$ 50$ for completing the final study questionnaire and US $\$ 50$ for returning Pivot Breath Sensor if they had not yet done so. Compensation was not associated with use of the various components of Pivot, level of engagement, or smoking/quitting status.

\section{Data Collection}

Data were collected electronically through participant input in the Pivot online registration form, Pivot app, and online questionnaires. Study data were imported directly into a secure database (PostgreSQL, PostgreSQL Global Development Group).

\section{Outcomes}

Outcomes from this follow-up phase of the study focus on smoking behavior, quit rates, continuous abstinence rates and duration, and predictors of abstinence. For smoking behavior, outcomes include CPD and quit attempts. A quit attempt was defined as going at least 1 day without smoking cigarettes, even a single puff. Quit rates were self-reported and include 7- and 30-day PPA. Participants were considered to have achieved 7-day (30-day) PPA if they answered "no" to the following question: "In the last 7 (30) days have you smoked any 
cigarettes, even a single puff?" As the Pivot program has no face-to-face contact, and data collection is achieved through remote means using the app and electronic questionnaires, biochemical verification of smoking status was not pursued in accordance with previous recommendations [26].

Although not listed as a preregistered outcome on Clinicaltrials.gov, we also evaluated continuous abstinence. The rationale for including continuous abstinence was to enhance the ability to compare outcomes in this study to those in other studies, to include an outcome that was a closer proxy for lifelong abstinence than PPA, and to include an outcome that was temporally closer to the Pivot program intervention than PPA [27]. Continuous abstinence includes the proportion of participants who achieved uninterrupted abstinence; a conservative definition was applied in which there was no grace period after the onset of abstinence, and any smoking (even a single puff) precluded designation of continuous abstinence. To be considered continuously abstinent, one had to report 30-day PPA on the end-of-Pivot questionnaire, 30-day PPA on the final questionnaire, and indicate a duration of abstinence that was equal to or greater than the number of days between the two questionnaires plus an additional 30 days. The average duration of abstinence is reported in those who achieved continuous abstinence. Finally, exploratory regression analyses were performed to identify the baseline characteristics associated with achievement of 7-day PPA, 30-day PPA, and continuous abstinence on the final questionnaire.

All participants were sent the end-of-Pivot and final follow-up questionnaires, regardless of their progress or completion status in the Pivot program.

\section{Sample Size}

Sample size was previously addressed [11]. A previous evaluation showed that attitudes toward quitting (motivation to quit, confidence to quit) are meaningful predictors of quit attempts [28]. On the basis of a previous assessment of 41 individuals using the first stage of Pivot (Explore), we estimated that the mean change in ratings assessing attitudes toward quitting (confidence to quit and expected difficulty maintaining quit) would be $\geq 1$ (SD 4) just before reaching the Quit stage of the program [29]. On the basis of these estimates, there was $80 \%$ power to detect a significant difference in these ratings with a sample size of 101 . As this was an initial study of the complete Pivot program, and in the context of known high attrition rates with mobile health apps [30-32], we applied conservative retention estimates drawn from other similar studies. Specifically, the target enrollment of 310 was estimated to yield at least 100 participants still engaged at the end of the Pivot program. The study enrolled 319 participants (ITT cohort) and 288 participants completed the final follow-up questionnaire (completer cohort).

\section{Analyses}

Changes in CPD were assessed from baseline to the final follow-up questionnaire. Participants served as their own controls, and comparisons were made to no change. To evaluate changes in CPD, repeated-measures linear mixed-model analyses were performed using a compound symmetric correlation matrix to model the repeated measures within participants. Because these measurements were taken at the same point in the study (not necessarily after the same amount of time, as progression through Pivot is self-paced), study stage (baseline vs final follow up) was used as a surrogate for time. To make specific comparisons across time, $F$ statistics were computed using the results from the model.

Analyses were conducted to calculate the mean (SD) for normally distributed variables for actual data or mean (SE) for modeled data. Median (IQR) values were used in instances of non-normally distributed variables. A paired one-sample $t$ test was used for numeric data. The Fisher exact or $\chi^{2}$ test was used for comparisons of categorical data. The McNemar test was used for two-category match-paired data. Cohen $\kappa$ statistic was used for three-category match-paired data.

In the assessment of quit rates (PPA), two sets of analyses were performed. In the ITT analysis, individuals who did not respond to PPA questions were assumed to be smoking. A study completer analysis was also performed, which only included individuals who completed the final follow-up questionnaire. Participants were sent the final follow-up questionnaire regardless of whether or not they completed the Pivot program. For additional assessments performed at the end of the study (quit attempts, proportion who reduced CPD by at least 50\%), a study completer analysis was performed. This analysis approach comports with previous reports assessing app-based digital cessation programs $[33,34]$.

We performed exploratory post-hoc analyses using univariate logistic regression to explore associations between baseline characteristics and smoking behavior outcomes. We evaluated each independent baseline variable as a predictor in a separate model, with the binary outcomes of 7-day PPA, 30-day PPA, and continuous abstinence. We then performed multivariate logistic regression using forward selection of baseline variables with the binary outcomes of 7-day PPA, 30-day PPA, and continuous abstinence. Analyses were conducted using SAS Version 9.4 (SAS Institute, Cary, NC). Statistical significance was set at $P<.05$.

\section{Results}

\section{Enrollment and Questionnaire Completion}

A total of 319 participants completed onboarding and comprised the ITT cohort. At the end of active participation in Pivot, at a mean of 4.1 (SD 1.4) months after enrollment, 85.3\% (272/319) of the participants completed the post-Pivot questionnaire [9]. At the end of the final follow-up period (3 months after completion of Pivot), at a mean of 7.2 (SD 1.2) months after enrollment, $90.3 \%$ (288/319) of participants completed the final follow-up questionnaire, who comprise the study completers cohort in this report. Study enrollment and attrition are depicted in the participant flow diagram shown in Figure 1. 
Figure 1. Study participant flow: Consolidated Standards of Reporting Trials (CONSORT) diagram. ITT: intention to treat; CPD: cigarettes per day.

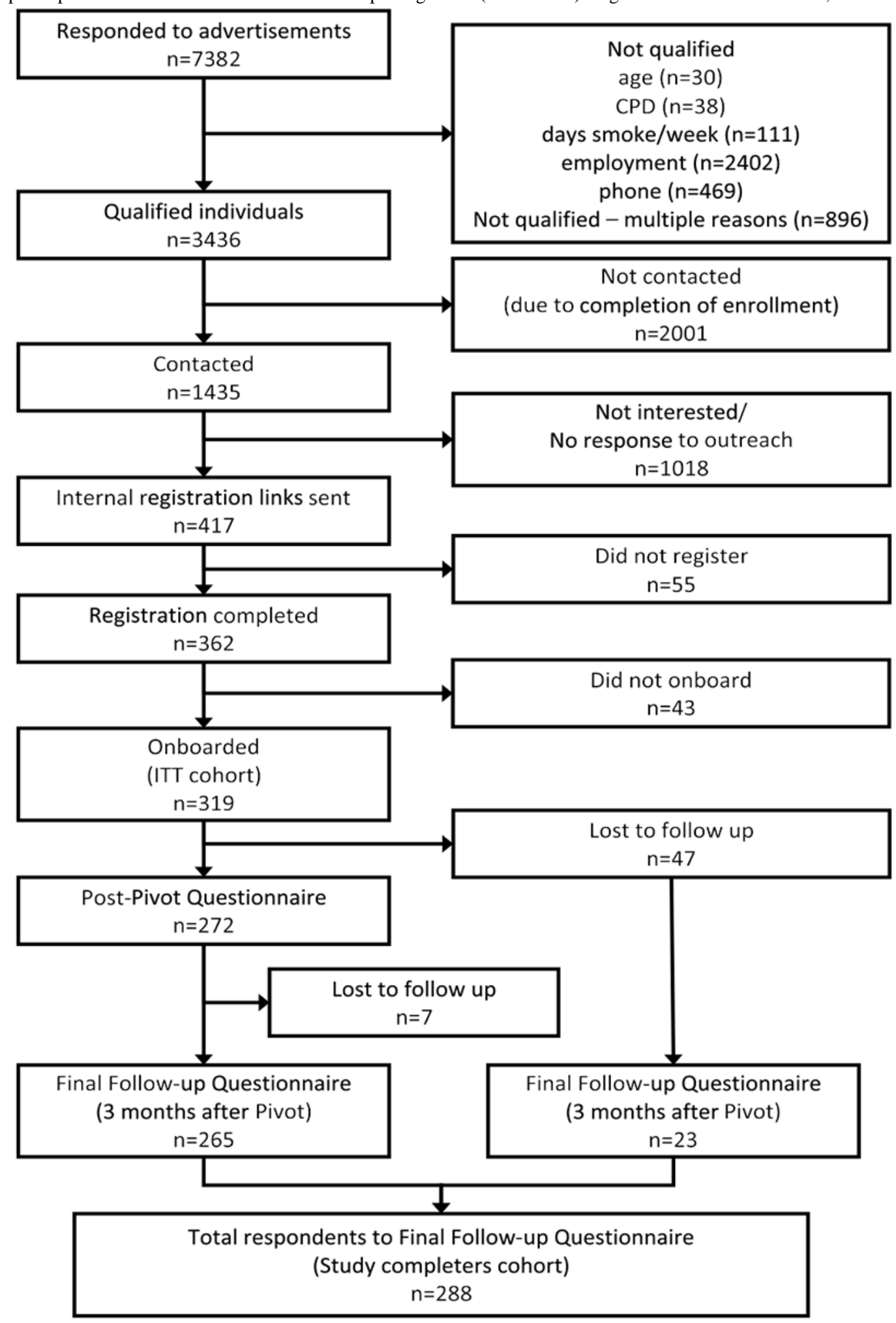

\section{Baseline Characteristics}

The study sample comprised $57.7 \%$ (184/319) women, had a mean age of 42.8 (SD 10.2) years, smoked a mean of 17.7 (SD 7.6) CPD at baseline, and had been smoking for a mean of 26.4 (SD 10.7) years. Participants represented 47 of the 50 US states; North Dakota, Nevada, and Arkansas were not represented. At baseline, 33.5\% (107/319) of participants indicated that they were seriously thinking of quitting smoking in the next 30 days,
$63.0 \%$ (201/319) indicated they were seriously thinking of quitting in the next 6 months, and 3.5\% (11/319) indicated they were not thinking of quitting smoking. On average, participants had made 2.1 (SD 3.3) quit attempts over the past 12 months.

\section{Smoking Behavior}

Repeated-measures linear mixed-model analysis was performed with estimated final follow-up CPD values compared with baseline. There was an estimated $52.6 \%$ (SE 2.1) reduction in 
CPD at final follow up $(P<.001)$, which persisted from the end of Pivot. Table 1 details the CPD at baseline, the end of Pivot, and at final follow up.

Among those who completed the final follow-up assessment, most $(152 / 288,52.8 \%)$ reduced their CPD by $\geq 50 \%$.

Focusing on the study completers who did not achieve at least 7 -day PPA at final follow up ( $\mathrm{n}=175), \mathrm{CPD}$ decreased by $22.7 \%$ (SD 37.0), and 22.3\% (39/175) reduced their CPD by $\geq 50 \%$.

As reported previously, among the 170 participants who completed the end-of-Pivot questionnaire and did not achieve abstinence, $25.9 \%$ (44/170) achieved $\geq 50 \%$ reduction in CPD. Of these participants, $95.5 \%$ (42/44) completed final follow up, at which time $66.7 \%(28 / 42)$ reported 7 -day PPA or $\geq 50 \%$ reduction in CPD. Specifically, 26.2\% (11/42) achieved 7-day PPA (16.7\%, 7/42 also achieved 30-day PPA) and 40.5\% (17/42) did not achieve PPA but reported $\geq 50 \%$ reduction in CPD.

Overall, most completers $(232 / 288,80.6 \%)$ reported making at least one quit attempt during the study with an average of 2.9 (SD 3.7) quit attempts made per participant.

Table 1. Changes in cigarettes per day (CPD) based on the linear mixed model (N=319).

\begin{tabular}{lllllll}
\hline Time point & CPD & \multicolumn{2}{c}{ Change in CPD vs baseline } & \multicolumn{2}{c}{ Percent change in CPD vs baseline } \\
& Mean (SE) & $P$ value $^{\mathrm{a}}$ & Mean (SE) & $P$ value $^{\mathrm{a}}$ & \multicolumn{2}{c}{ Mean $(\mathrm{SE})^{P \text { value }^{\mathrm{a}}}$} \\
\hline Baseline & $17.7(0.43)$ & N/A $^{\mathrm{b}}$ & N/A & N/A & N/A & N/A \\
End of Pivot & $8.0(0.45)$ & $<.001$ & $-9.7(0.42)$ & $<.001$ & $-54.5(2.2)$ & $<.001$ \\
Final follow up & $8.5(0.44)$ & $<.001$ & $-9.2(0.41)$ & $<.001$ & $-52.6(2.1)$ & $<.001$ \\
\hline
\end{tabular}

${ }^{\mathrm{a} C}$ Compared to baseline.

${ }^{\mathrm{b}} \mathrm{N} / \mathrm{A}$ : not applicable.

\section{Quit Rates}

Quit rates increased from the end of Pivot to final follow up. Specifically, at final follow up, 35.4\% (113/319) achieved 7-day PPA and 31.3\% (100/319) achieved 30-day PPA using ITT analysis. These rates increased from those obtained at the end of Pivot, when the 7-day PPA was $32.0 \%(102 / 319)$ and the 30-day PPA was 27.6\% (88/319).

Similarly, at final follow up, 39.2\% (113/288) achieved 7-day PPA and $34.7 \%$ (100/288) achieved 30-day PPA, using the study completer analysis. These rates increased from those obtained at the end of Pivot, when the 7-day PPA was $37.5 \%$ $(102 / 272)$ and the 30-day PPA was $32.4 \%$ (88/272).

Assessing only the 265 participants who completed both the end-of-Pivot and final follow-up questionnaires, $41.5 \%$ (110/265) achieved 7-day PPA and 37.0\% (98/265) achieved 30-day PPA. Among the 23 participants who did not complete the end-of-Pivot questionnaire but did complete the final follow up, 20 were still smoking, 1 reported 7-day PPA, and 2 reported 30-day PPA (as well as 7-day PPA) at final follow up (Figure 2).

Of the 88 participants who achieved 30-day PPA at the end of Pivot, $92.0 \%$ (81/88) reported 30-day PPA at final follow up.

From the end of Pivot to final follow up, there were 23 newly abstinent participants. Specifically, among the 217 participants who had not achieved at least 7-day PPA at the end of Pivot, $10.6 \%$ (23/217) reported abstinence at final follow up. Focusing on these 23 individuals, 15 achieved 30-day PPA (as well as 7-day PPA) and 8 achieved 7-day PPA (Figure 2).

Using all available data, $42.0 \%$ (134/319, ITT) achieved 7-day PPA and $35.4 \%(113 / 319$, ITT) achieved 30-day PPA at some point during the study. 
Figure 2. Participant smoking status at the end of Pivot and at final follow up.

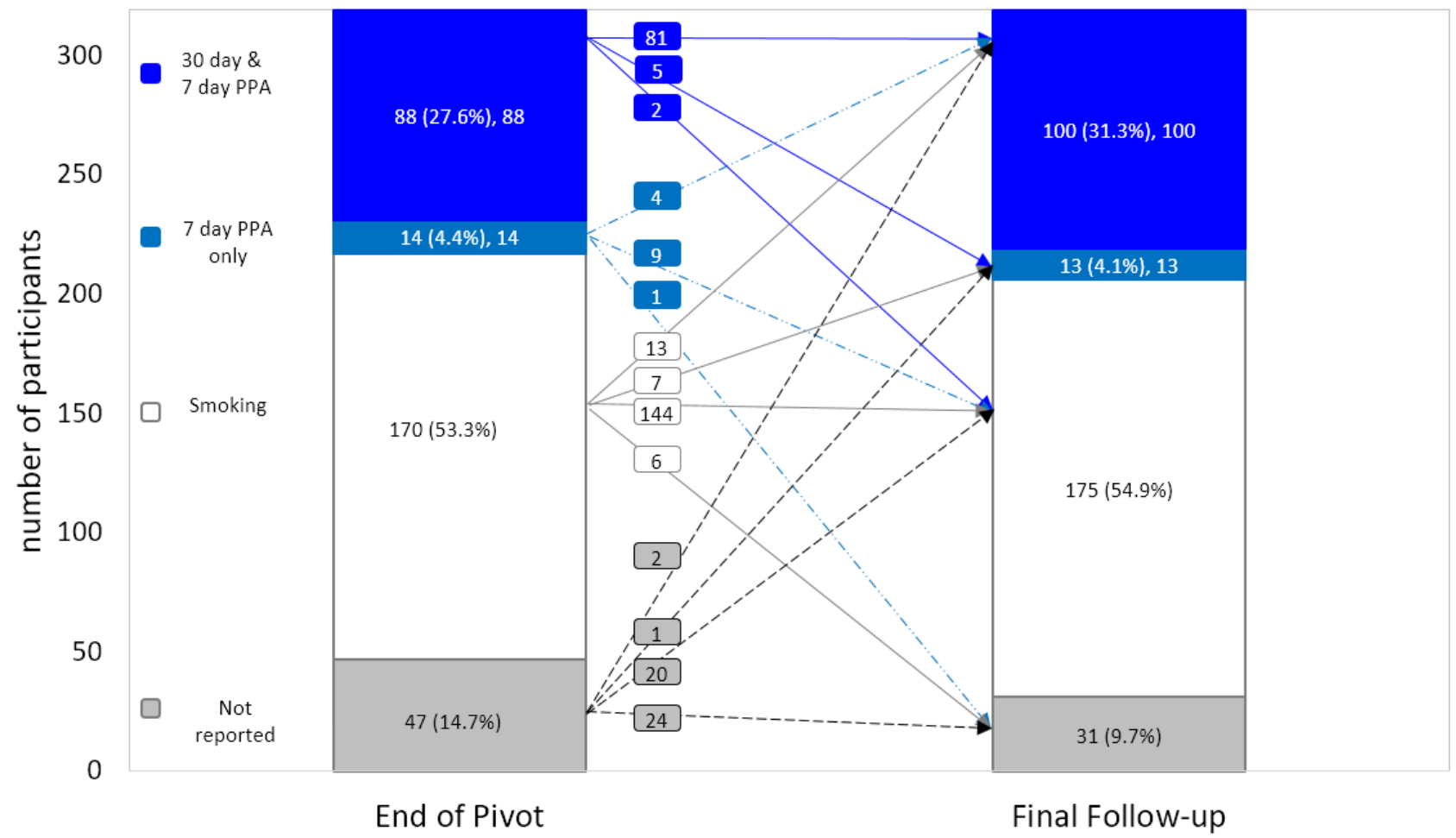

\section{Continuous Abstinence}

Continuous abstinence was reported in 76 participants. Table 2 details continuous abstinence rates in various study subgroups.

Among all study participants, approximately a quarter achieved continuous abstinence. Among those who completed the final follow-up questionnaire, just over a quarter achieved continuous abstinence. Focusing on participants who made at least one quit attempt, nearly a third achieved continuous abstinence. Focusing on participants who reported 30-day PPA at the end of Pivot, the continuous abstinence rate was very high. The mean duration of continuous abstinence in this group was 5.8 (SD 0.6) months.

Table 2. Continuous abstinence rates in various study subgroups.

\begin{tabular}{lll}
\hline Study subgroup & $\mathrm{N}$ & Continuous abstinence rate, $\mathrm{n}(\%)$ \\
\hline Enrolled (intention to treat) & 319 & $76(23.8)$ \\
Completed final follow-up questionnaire (completers) & 288 & $76(26.4)$ \\
Made at least one quit attempt & 232 & $76(32.8)$ \\
Achieved 30-day point prevalence abstinence at the end of Pivot & 88 & $76(86.4)$ \\
\hline
\end{tabular}

\section{Predictors of Abstinence}

Focusing on all 319 participants who enrolled in the study, exploratory univariate regression analyses were performed to examine associations between participant baseline variables and final follow-up achievement of 7-PPA, 30-day PPA, and continuous abstinence; results are detailed in Table 3.
Lower baseline CPD, higher confidence to quit, and lower perceived difficulty maintaining quit were associated with an increased likelihood of achieving 7-day PPA, 30-day PPA, and continuous abstinence. Non-White Hispanic/Latino/Latina/ Spanish origin was associated with a higher likelihood of achieving 7-day PPA, 30-day PPA, and continuous abstinence; however, this association should be considered with caution due to the low number of participants in this category $(15 / 319$, $4.7 \%)$. 
Table 3. Univariate logistic regression analyses of baseline predictors of 7-day PPA, 30-day PPA, and continuous abstinence at final follow up among all study participants $(\mathrm{N}=319)$.

\begin{tabular}{|c|c|c|c|c|c|c|c|}
\hline \multirow[t]{2}{*}{ Baseline variable } & \multirow[t]{2}{*}{$\mathrm{N}$} & \multicolumn{2}{|l|}{ 7-day $\mathrm{PPA}^{\mathrm{a}}$} & \multicolumn{2}{|l|}{ 30-day PPA } & \multicolumn{2}{|c|}{ Continuous abstinence } \\
\hline & & $\mathrm{OR}^{\mathrm{b}}(95 \% \mathrm{CI})$ & $P$ value $\mathrm{c}^{\mathrm{c}}$ & OR $(95 \% \mathrm{CI})$ & $P$ value & OR $(95 \% \mathrm{CI})$ & $P$ value \\
\hline Age & 319 & $0.99(0.97-1.01)$ & .33 & $0.98(0.96-1.00)$ & .08 & $0.98(0.96-1.01)$ & .12 \\
\hline \multicolumn{8}{|l|}{ Gender } \\
\hline Male & 135 & 1 [Reference] & $\mathrm{N} / \mathrm{A}^{\mathrm{d}}$ & 1 [Reference] & N/A & 1 [Reference] & N/A \\
\hline Female & 184 & $1.39(0.87-2.23)$ & .17 & $1.30(0.80-2.11)$ & .29 & $1.08(0.64-1.83)$ & .76 \\
\hline \multicolumn{8}{|l|}{ Race/ethnicity } \\
\hline White & 264 & 1 [Reference] & N/A & 1 [Reference] & N/A & 1 [Reference] & N/A \\
\hline American Indian/Alaska Native & 4 & $0.66(0.07-6.39)$ & .72 & $0.78(0.08-7.62)$ & .83 & $1.21(0.12-11.9)$ & .81 \\
\hline Asian & 5 & $0.49(0.05-4.46)$ & .53 & $0.59(0.06-5.32)$ & .63 & $0.91(0.10-8.28)$ & $>.99$ \\
\hline Black/African American & 22 & $1.36(0.56-3.31)$ & .50 & $1.09(0.43-2.78)$ & .85 & $2.08(0.83-5.19)$ & .20 \\
\hline Hispanic/Latino/Latina/Spanish origin & 15 & $3.93(1.31-11.9)$ & .02 & $3.51(1.21-10.20)$ & .02 & $3.18(1.11-9.13)$ & .03 \\
\hline Native Hawaiian or other Pacific Islander & 2 & $1.97(0.12-31.8)$ & .63 & $2.34(0.15-37.90)$ & .55 & $-^{\mathrm{e}}$ & - \\
\hline Other race, ethnicity, or origin & 7 & $0.79(0.15-4.14)$ & .78 & $0.94(0.18-4.90)$ & .94 & $1.45(0.28-7.68)$ & .66 \\
\hline \multicolumn{8}{|l|}{ Education } \\
\hline Bachelor's degree or greater & 96 & 1 [Reference] & N/A & 1 [Reference] & N/A & 1 [Reference] & N/A \\
\hline Less than bachelor's degree & 223 & $1.60(0.95-2.70)$ & .08 & $1.44(0.84-2.45)$ & .18 & $1.52(0.84-2.76)$ & .16 \\
\hline \multicolumn{8}{|l|}{ Income (US \$) } \\
\hline$<50,000$ & 136 & 1 [Reference] & N/A & 1 [Reference] & N/A & 1 [Reference] & NA \\
\hline$>50,000$ & 173 & $0.79(0.50-1.27)$ & .33 & $0.77(0.47-1.25)$ & .29 & $1.21(0.70-2.10)$ & .49 \\
\hline Did not answer & 10 & $1.08(0.29-4.00)$ & .91 & $0.81(0.20-3.28)$ & .77 & $1.73(0.42-7.14)$ & .45 \\
\hline Cigarettes per day & 319 & $0.96(0.93-0.99)$ & .01 & $0.97(0.94-1.00)$ & .048 & $0.95(0.91-0.99)$ & .01 \\
\hline Years smoking & 319 & $0.99(0.97-1.01)$ & .44 & $0.98(0.96-1.01)$ & .18 & $0.98(0.95-1.00)$ & .10 \\
\hline Quit attempts in last 12 months & 319 & $1.03(0.97-1.11)$ & .33 & $1.04(0.97-1.11)$ & .32 & $1.04(0.97-1.11)$ & .31 \\
\hline \multicolumn{8}{|l|}{ Stage of change } \\
\hline Yes, within the next 30 days & 107 & 1 [Reference] & N/A & 1 [Reference] & N/A & 1 [Reference] & NA \\
\hline Yes, within the next 6 months & 201 & $0.88(0.54-1.43)$ & .59 & $0.96(0.58-1.60)$ & .87 & $1.15(0.66-2.00)$ & .78 \\
\hline No, not thinking of quitting & 11 & $0.96(0.26-3.48)$ & .95 & $1.23(0.34-4.48)$ & .76 & $0.77(0.16-3.80)$ & .35 \\
\hline Confidence to quit & 319 & $1.11(1.02-1.21)$ & .02 & $1.11(1.02-1.21)$ & .02 & $1.17(1.06-1.28)$ & .001 \\
\hline Perceived difficulty maintaining quit & 319 & $1.14(1.04-1.25)$ & .004 & $1.18(1.08-1.30)$ & $<.001$ & $1.19(1.08-1.31)$ & .003 \\
\hline
\end{tabular}

${ }^{\mathrm{a} P P A}$ : point prevalence abstinence.

${ }^{b}$ OR: odds ratio.

${ }^{\mathrm{c}} P$ values are based on $95 \%$ Wald confidence limits.

${ }^{\mathrm{d}} \mathrm{N} / \mathrm{A}$ : not applicable.

e_-: No participants in this category.

Focusing specifically on the 88 participants who achieved 30-day PPA at the end of Pivot, exploratory univariate regression analyses were performed to examine associations between participant baseline variables and final follow-up achievement of continuous abstinence. None of the evaluated baseline variables was found to be associated with continuous abstinence.

In multivariate regression analyses, lower baseline CPD (OR 0.96 , 95\% CI $0.93-0.99 ; P=.02)$, lower perceived difficulty maintaining quit (OR 1.13, 95\% CI 1.03-1.24; $P=.01$ ), and higher education (OR 1.72, 95\% CI 1.01-2.94; $P=.047$ ) were associated with an increased likelihood of achieving 7-day PPA. Lower perceived difficulty maintaining quit (OR $1.18,95 \% \mathrm{CI}$ $1.08-1.30 ; P<.001)$ was associated with achieving 30 -day PPA. Lower perceived difficulty maintaining quit (OR 1.13, 95\% CI $1.02-1.26 ; P=.02$ ) and higher confidence to quit (OR 1.12, 95\% CI 1.01-1.24; $P=.04$ ) were associated with achieving continuous abstinence. Finally, no baseline variables were predictive of 
continuous abstinence among the 88 individuals who achieved 30-day PPA at the end of Pivot.

\section{Discussion}

\section{Principal Findings}

The present report details longer-term follow-up outcomes from a prospective cohort study of 319 adult smokers who underwent the Pivot smoking cessation program. These outcomes, from a mean of 7.2 (SD 1.2) months postenrollment, focus on smoking behavior, quit rates via PPA, continuous abstinence rates and duration, and predictors of abstinence. To our knowledge, this is the first study assessing longer-term outcomes in a mobile smoking cessation program such as Pivot, which includes biofeedback via a personal portable $\mathrm{CO}$ breath sensor, education and guidance through a smartphone app, and support through text-based human coaching. At final follow up, CPD were reduced by approximately half, most participants had made a quit attempt, quit rates had increased from the end of the Pivot program, and approximately a quarter of participants achieved continuous abstinence. Regression analyses showed that lower CPD, attitudes toward quitting reflecting higher self-efficacy, and higher education level were associated with achieving abstinence. Overall, final follow-up outcomes persisted or improved when compared to previous outcomes from the end of the Pivot program.

\section{Specific Findings}

\section{Scope for Comparison}

Comparison with other studies is limited due to the novelty of digital smoking cessation programs that comprise a smartphone app, human-delivered text-based coaching, and a personal biofeedback device. In addition, among the few studies that did include smoking cessation interventions comparable to Pivot, differences in study design or population are significant enough to make comparison challenging. Taking these factors into consideration, we review the outcomes of our study with others below, with consideration of studies that employed a smoking cessation intervention similar to Pivot, expanding the assessment to include a broader group of digital smoking cessation interventions, and finally considering Pivot in the context of different types of smoking cessation interventions.

\section{CPD Reduction}

At final follow up, participants reduced CPD by $52.6 \%$. Among those who did not achieve PPA, CPD were reduced by $22.7 \%$, and $22.3 \%$ (39/175) reduced their CPD by $\geq 50 \%$. Two additional studies have employed smoking cessation interventions similar to Pivot and included changes in CPD as an outcome. Webb et al [35] performed an RCT in adult smokers in the United Kingdom randomized to a digital therapeutic intervention (treatment, $n=265$ ) or very brief advice (control, $n=265$ ). The digital therapeutic intervention for smoking cessation comprised a smartphone app delivering cognitive behavioral therapy content, human coaching via phone and in-app chat, craving tools, and tracking capabilities. The control intervention was very brief advice applying the Ask, Advise, Act model. Half of the participants received a personal $\mathrm{CO}$ breath sensor that was used to measure their exhaled $\mathrm{CO}$ and validate self-reported abstinence. Eligibility criteria included readiness to quit in the next 30 days. Participants had an in-person baseline visit, and then self-reported outcomes via phone or online at 4 weeks after the quit date. Participants set a quit date an average 16 days postrandomization. All participants were offered free nicotine replacement therapy (NRT) for 3 months, which was used by $59.1 \%(133 / 225$, treatment) and 63.2\% (146/231, control) of participants (risk ratio $0.94,95 \%$ CI $0.81-1.08$ ). At 4 weeks post quit date, mean CPD were reduced in those who failed to achieve abstinence by $48.1 \%$ in the treatment group and by $48.9 \%$ in the control group. The provision of NRT that was used by most participants, the 1-month endpoint that occurred during the active treatment phase of the intervention, and inclusion only of individuals ready to quit smoking in the next 30 days in the Webb study are notable study design differences that likely contribute to differences in CPD reduction from those found in the present study.

The second study that evaluated a smoking cessation intervention similar to Pivot, performed by Krishnan et al [36], was an RCT in which adult smokers in the United States received brief advice along with a personal $\mathrm{CO}$ breath sensor and the COach2Quit app (intervention, $n=50$ ) or brief advice only (control, $n=52$ ). The Coach2Quit app prompted the user to set a quit date, provided reminders to complete two breath samples a day, sent response messages from a text message library to users after breath samples were provided based on their $\mathrm{CO}$ results, and provided graphical representation of user $\mathrm{CO}$ readings. Eligibility criteria included willingness to set a quit date within 2 weeks of the baseline assessment. Follow-up visits were conducted at 14 days and 30 days from baseline. The median CPD among all participants decreased from 10 at baseline to 5 in the intervention group and to 6 in the control group at 30 days, for an approximate reduction of $40 \%-50 \%$. This is in range with the $52.6 \% \mathrm{CPD}$ reduction for all participants found in our study; however, it is unknown if and how CPD reduction changed in the Krishnan study after the active intervention phase.

Looking more broadly at digital health interventions, Garrison et al [37] recently reported results from an RCT comparing the efficacy of 22 days of mobile mindfulness training through the Craving to Quit app with app-based experience sampling $(n=143)$ versus 22 days of app-based experience sampling only $(n=182)$. At 6 months, CPD were reduced but not different between the two groups; the app group reduced CPD by $43.8 \%$ (from 16.0, SD 7.1 to 9.0, SD 7.8) and the experience sampling-only group reduced CPD by $45.7 \%$ (from 16.2, SD 8.2 to 8.8, SD 9.0). Finally, Alessi et al [38] performed an RCT with 90 participants randomized to usual care and ecological monitoring with abstinence reinforcement (mobile health reinforcement) or without reinforcement (mobile health monitoring). Usual care was 8 weeks of transdermal nicotine and twice-weekly telephone counseling. Ecological monitoring was administered through an interactive voice response system that prompted participants to conduct 1-3 CO breath tests daily, video record the process, and submit the videos. Participants in the abstinence reinforcement group could earn prizes for on-time $\mathrm{CO}$ breath tests with $\mathrm{CO}$ values consistent with abstinence. At 6 months, CPD were reduced by $47 \%$ (baseline 17.6 to 9.3 CPD 
at 6 months) in the mobile health reinforcement group and by $55 \%$ (baseline 20.0 to 9.0 at 6 months) in the mobile health monitoring group.

Overall, assessing the present and aforementioned studies, digital smoking cessation interventions have reported CPD reduction by about half at 6 months. Studies that have assessed interventions similar to Pivot have reported similar reductions achieved earlier, at 1 month; however, the durability of the reduction in these instances is unknown.

\section{PPA Rates}

PPA between the end of Pivot and final follow up 3 months later increased; using ITT analyses, 35.4\% (113/319) achieved 7-day PPA and 31.3\% (100/319) achieved 30-day PPA at final follow up, compared to $32.0 \%$ (102/319) and 27.6\% (88/319), respectively, at the end of the Pivot program.

Comparing our $35.4 \%$ final follow-up 7-day PPA rate to other studies with interventions similar to Pivot, Webb et al [35] reported a $44.5 \%$ 7-day PPA rate at 1 month. The approximate $35 \%-45 \%$ 7-day PPA range seems within reason when considering that the Webb study included the provision of NRT and required participants to be ready to quit smoking within the next 30 days at enrollment for study eligibility, acknowledging that longer-term data from the Webb study will be informative. Masaki et al [39] performed an RCT of adult smokers recruited from smoking cessation clinics in Japan. Participants were randomized to the intervention, which included a 12-week standard smoking cessation treatment plus the CureApp Smoking Cessation (CASC) system $(\mathrm{n}=285)$, or to the control, which consisted of the 12-week standard smoking cessation treatment plus a control app $(n=287)$. The CASC system comprised a smartphone app, paired mobile exhaled CO breath sensor, connected cloud system to upload data, and web-based PC software for physicians. The 12-week standard smoking cessation treatment included five in-person visits with counseling and physician-provided pharmacotherapy of varenicline or nicotine patch. The CASC system and control app were used for 24 weeks. Eligibility criteria included intention to quit smoking immediately. Seven-day PPA at 24 weeks was achieved in $72.3 \%$ of the CASC intervention group participants and in $58.2 \%$ of the control group participants $(P<.01)$. Considering the 58.2\% 7-day PPA rate in the control arm, this high 7-day PPA rate in the CASC intervention arm likely reflects what a program similar to Pivot adds when used as a supplement to a traditional intensive smoking cessation program in individuals ready to quit smoking.

Looking more broadly at outcomes from digital smoking cessation interventions, 7-day PPA at 6 months range from $9.8 \%$ to $29.6 \%$, with most falling between $17 \%$ and $25 \%$ $[10,37,38,40,41]$. Our higher 7 -day PPA rate of $35.4 \%$ aligns with expectations considering Pivot's additional features of the personal breath sensor and coaching.

Focusing on 30-day PPA, 31.3\% (100/319) achieved this outcome at final follow up in our study. We did not find comparable data in studies that included interventions similar to Pivot. Broadening the scope to include additional digital smoking cessation interventions, 6-month 30-day PPA outcomes ranged from $12.9 \%$ to $21.8 \%$, with an additional study reporting a $26.2 \% 30$-day PPA rate at 8 weeks $[10,34,40]$. Similar to our expectation, we believe that the additional features of Pivot beyond the app likely contributed to the higher 30-day PPA rate.

\section{Continuous Abstinence}

Continuous abstinence at final follow up was reported in about a quarter of all participants $(76 / 319,23.8 \%)$ and in about a third of those who made a quit attempt $(32.8 \%, 76 / 232)$ in our study. Masaki et al [39] reported that $63.9 \%$ of participants achieved continuous abstinence at 6 months. These differences in continuous abstinence likely reflect outcomes when Pivot is used as the sole intervention among smokers who represent the entire spectrum of readiness to quit in contrast to when a Pivot-like program is used as an adjunct to an intensive smoking cessation program among individuals ready to quit smoking. Expanding the scope of studies to the broader category of digital smoking cessation interventions, the rates for continuous abstinence at 6 months range from $4.8 \%$ to $19.8 \%$, with most falling between $10 \%$ and $16 \%[37,38,40,42]$. Overall, there appears to be a trend reflecting the intensity and comprehensiveness of the intervention, with lower-intensity programs reporting continuous abstinence at 6 months in about $10 \%-16 \%$ of participants, mid-intensity programs such as Pivot reporting continuous abstinence in about a quarter of all participants or a third of participants who make a quit attempt, and high-intensity programs achieving continuous abstinence in over half of participants.

Considering Pivot in the context of different types of smoking cessation interventions, we turn to meta-analyses to provide insight on longer-term outcomes. Whittaker et al [9] published a meta-analysis in 2019 assessing automated mobile phone text messaging and app-based interventions for smoking cessation. Long-term abstinence (defined as smoking cessation at 6 months or longer using the most stringent measure available) was higher in text messaging-based interventions compared to minimal smoking cessation support (13 studies, 14,133 participants; RR $1.54,95 \%$ CI $1.19-2.00 ; \mathrm{I}^{2}=71 \%$ ). Evaluating both high- and low-intensity text message-based interventions using data pooled from three studies, the authors reported average $\geq 6$-month abstinence rates of $26.6 \%-27.1 \%$. A similar effect was not seen for comparison of smartphone app interventions to lower-intensity smoking cessation support (5 studies, 3079 participants; RR 1.00, 95\% CI 0.66-1.52; $\mathrm{I}^{2}=59 \%$ ); however, the authors noted the need for additional data to further assess these interventions, as this particular evaluation comprised 5 studies with many additional studies ongoing at the time of publication.

Matkin et al [43] published a meta-analysis in 2019 on telephone counseling for smoking cessation. In studies that recruited smokers who underwent proactive telephone counseling (ie, counseling that was not delivered through calling a helpline), the counseling increased quit rates (RR 1.25, 95\% CI 1.15-1.35; $\mathrm{I}^{2}=52 \%$; 65 trials, 41,233 participants). The authors reported that based on a control group quit rate of $11 \%$, telephone counseling would produce an absolute increase of $2 \%-4 \%$, resulting in a $\geq 6$-month quit rate of $13 \%$ - $15 \%$. In a 2017 
meta-analysis, Lancaster et al [6] reported that individual counseling increases the likelihood of cessation compared with less intensive support. Based on pooling 27 trials comprising 11,100 participants, individual counseling, when used independently of pharmacotherapy, was estimated to increase cessation by $40 \%$ to $80 \%$ after at least 6 months. Assuming a control group quit rate of $7 \%$ from a brief intervention, individual counseling would be expected to result in an absolute increase of $3 \%-5 \%$, yielding a $10 \%-12 \%$ quit rate. Finally, in a 2019 meta-analysis, Hartmann-Boyce et al [5] reported that NRT increased quit rates compared to control, by an amount that depended on the baseline quit rate. For example, for an expected quit rate of $3 \%-5 \%$ in people attempting to quit on their own, NRT might increase the quit rate by $2 \%-3 \%$. However, if the expected quit rate of a population was $15 \%$, another $8 \%$ might be expected to quit with NRT use.

Summarizing these findings from meta-analyses, long-term quit rates for various types of smoking cessation interventions include $10 \%-15 \%$ for telephone or individual counseling alone, $26 \%-27 \%$ for automated text messaging, and $5 \%$ to more than $23 \%$ for NRT alone (depending on the expected quit rate in the population at baseline). Acknowledging that consideration of these data is primarily to establish context for the outcomes of Pivot, and that direct comparison of our cohort study with large meta-analyses is not appropriate, we believe that our $23.8 \%$ continuous abstinence rate in all participants is reasonable and encouraging. As a program that includes established evidence-based components such as coaching, as well as novel aspects that aim to leverage nascent but promising approaches to smoking cessation such as biofeedback via a personal breath sensor, we would expect to improve upon existing interventions. Certainly, this should be born out with future additional investigation and data.

\section{Abstinence Duration}

Hughes et al [44] established the significance of abstinence duration, reporting that abstinence stabilizes at about 6 months. Zhou et al [45] reported similar findings in their evaluation of 2431 smokers who intended to stop smoking in the next 3 months. They followed these individuals periodically for 18 months via internet questionnaires; after 6 months of abstinence, the relapse rate dropped below $20 \%$ and the cumulative relapse rate reached a plateau. Herd et al [46] detailed similar findings in a longitudinal survey of 1296 ex-smokers in the general population who quit on their own (not in an interventional study), reporting that a duration of abstinence of 31-182 days was associated with a $58 \%$ continuous abstinence rate, whereas duration of abstinence of 183-365 days was associated with a $78 \%$ continuous abstinence rate. These data bring further confidence to our results; with a continuous abstinence duration of approximately 6 months (mean 5.8, SD 0.6 months), there is reason to expect stability in our continuous abstinence rate.

Approaching continuous abstinence from a different angle, in a systematic review, Hughes et al [27] assessed the relationship between PPA rates and prolonged abstinence in studies with point prevalence durations of up to 7 days and follow ups of at least 6 months from the quit date. They reported that point prevalence and prolonged abstinence were highly correlated
( $r=0.88)$ and that prolonged abstinence averaged 0.74 that of PPA, indicating that approximately three-quarters of those who achieve point prevalence will achieve prolonged abstinence. In the most comparable analysis from our data, 79.4\% (81/102) of study participants who achieved 7-day PPA at the end of Pivot achieved continuous abstinence of approximately 6 months duration (mean 5.6, SD 0.7 months), findings which align with those reported by Hughes et al [27].

\section{Predictors of Abstinence}

Exploratory univariate regression modeling demonstrated that among all study participants, lower baseline CPD, higher self-efficacy through confidence to quit, and lower perceived difficulty of maintaining quit were associated with achieving 7-day PPA, 30-day PPA, and continuous abstinence at final follow up, approximately 7 months from enrollment. Multivariate regression modeling found that lower perceived difficulty of maintaining quit was associated with 7- and 30-day PPA and continuous abstinence, lower CPD and higher education were associated with 7-day PPA, and higher confidence to quit was associated with continuous abstinence.

These results are consistent with previous findings. In the aforementioned study of 1296 ex-smokers by Herd et al [46], relapse was associated with lower abstinence self-efficacy. Smit et al [47] assessed predictors of successful quit attempts among 570 smokers motivated to quit in the next 6 months who were randomized to the control group in a web-based smoking cessation intervention study. They reported that self-efficacy was the main factor in predicting quit attempt success.

Nicotine dependence has also been shown to be a predictor of successful cessation [26]. In a systematic literature review of adult general population smokers, Vangeli et al [28] reported that cigarette dependence consistently predicted success after a quit attempt. Hymnowitz et al [48] performed a cohort tracking telephone survey in 13,415 smokers over 5 years. They reported that predictors with the largest RR values for smoking cessation were those associated with nicotine dependence, including CPD. Thereby, it is not surprising that in our study, lower baseline CPD was associated with achieving abstinence.

Finally, higher education has been shown to be a predictor for success in cessation. In a study including 887 smokers undergoing a smoking cessation program through their workplace, a higher educational level (OR 1.81, 95\% CI 1.06-3.09, $P=.03$ ) predicted successful cessation [49]. In a study including 4397 smokers who participated in a two-armed RCT assessing computer-tailored smoking cessation advice in the United Kingdom, Kale et al [50] reported that a higher reading level was associated with successful quitting (OR 1.62, 95\% CI 1.19-2.21). Reid et al [51] evaluated smokers in Canada, the United Kingdom, Australia, and the United States from the first five waves (2002-2006/2007) of the International Tobacco Control Four Country Survey (35,532 observations from 16,458 respondents). They reported that smokers with a high education level were more likely to be abstinent for 1 and 6 months (OR 1.20, 95\% CI 1.00-1.44 and OR 1.30, 95\% CI 1.05-1.62, respectively). 


\section{Limitations}

Limitations of this study were discussed previously [11] and include limited representation of individuals who use Android smartphones, are employed less than 20 hours per week, and are not seriously thinking of quitting smoking. Regarding the smartphone platform, Ubhi et al [52] reported differing behavior among users of a smoking cessation app (SmokeFree28 app) between Android and iOS users, with iOS users being more likely to have made a quit attempt in the last 12 months and set their quit date on the day of registration, and Android users being more likely to have used smoking cessation medication in their quit attempt. Baseline intention to quit (Stage of Change) as well as factors associated with socioeconomic status have been documented as predictors for quit attempts and success in quitting smoking [46,47,49-51]. Collectively, these findings highlight the need for additional data on the Pivot program in members of these groups with limited representation in this study.

In addition, although multiple efforts were taken to minimize the impact of participant study payments, including keeping individual payments under US \$50, incorporating a several-week delay between questionnaire completion and payment receipt, and not linking payment to use of program components or smoking outcomes, we cannot exclude some influence of study payment on participant behavior.

Owing to the sequential nature of Pivot, we elected to obtain outcome data as participants advanced through the self-paced program. The final follow-up data in our study is from a mean 7.2 (SD 1.2) months postenrollment, a time point that we believe was reasonable to consider with 6-month outcomes from other studies. This approach is different from the more traditional 30-, 90-, and 180-day assessments that are linked directly to enrollment date, and this difference is worth acknowledging as it limits direct comparison between studies.

The self-reported nature of smoking status is also a possible limitation. Biochemical verification of results was not sought for a few reasons. First, this study comprised general population smokers and was conducted entirely remotely with all data collection performed electronically via online questionnaires and through the Pivot app. Based on these study characteristics, biochemical verification was not pursued in accordance with previous recommendations [26,53]. Second, the breath sensor was employed as an educational and motivational tool in this study. We were concerned that implementing verification of smoking status with the breath sensor would instill a sense of policing that might detract from participant perception and experience of the sensor. Finally, while we acknowledge the possible limitation of over-reporting cessation with self-reporting smoking status, the literature suggests that the rate of occurrence is less than $10 \%$ in general population smokers. Specifically, Gorber et al [54] performed a systematic review of 54 studies to measure the concordance between self-reported smoking status and smoking status biochemically verified through measures of cotinine. The mean difference between self-reported and measured prevalence estimates was $-4.8 \%$ for studies that measured cotinine in saliva; $-6.2 \%$ for those measuring cotinine in serum, blood, or plasma; and $-9.4 \%$ when cotinine was measured in urine.

Finally, although participants were provided education about NRT via the Pivot app and coaching in the study, they were not provided NRT. Given the well-established positive impact of NRT on smoking cessation [5,18-21], inclusion of NRT in Pivot would have likely further increased quit rates. The provision of NRT has since been added to the Pivot program; accordingly, future studies are warranted.

\section{Conclusions}

This follow-up study provides the first longer-term outcomes of Pivot, an inclusive and innovative smoking cessation program that employs a smartphone app, biofeedback through a personal portable $\mathrm{CO}$ breath sensor, and in-app text-based coaching. At final follow up, approximately 7 months after enrollment, quit rates increased and continuous abstinence was favorable. Most participants made a quit attempt. The emergence of newly abstinent participants and persistent decreases in CPD 3 months after active program participation underscore the sustained learning and impact from Pivot. These results validate earlier findings, and suggest that Pivot is an effective and durable solution for smoking cessation.

\section{Acknowledgments}

The authors thank Heather Patrick, PhD, for her critical contributions to the study design, early data analysis, and drafting of the previous manuscript. We also thank Lydia Tesfamariam for assistance with recruiting, collaborative tracking of participants, study payments, and database management and analysis. The work of JG is supported, in part, by National Institutes of Health Grant P30 DK034987.

\section{Authors' Contributions}

JM, DU, and CF designed the study. JM and CF recruited participants. JM ran the study. CF managed the database and performed data analyses. JG performed the statistical analyses. JM prepared the original draft of the manuscript. CF, DB, DU, and JG reviewed and edited the manuscript before submission.

\section{Conflicts of Interest}

JM, CF, DB, and DU are current employees of Carrot Inc, the developer of the app and devices used in this study. They receive salary and stock options from Carrot Inc. DU is the President and CEO of Carrot Inc and an investor in the company.

\section{References}


1. National Center for Chronic Disease Prevention and Health Promotion (US) Office on Smoking and Health. The Health Consequences of Smoking - 50 Years of Progress A Report of the Surgeon General. Atlanta, GA: Centers for Disease Control and Prevention; 2014. URL: https://www.ncbi.nlm.nih.gov/books/NBK179276/ [accessed 2021-02-06]

2. Cornelius ME, Wang TW, Jamal A, Loretan CG, Neff LJ. Tobacco Product Use Among Adults - United States, 2019. MMWR Morb Mortal Wkly Rep 2020 Nov 20;69(46):1736-1742. [doi: 10.15585/mmwr.mm6946a4] [Medline: 33211681]

3. Jha P, Ramasundarahettige C, Landsman V, Rostron B, Thun M, Anderson RN, et al. 21st-century hazards of smoking and benefits of cessation in the United States. N Engl J Med 2013 Jan 24;368(4):341-350. [doi: 10.1056/NEJMsa1211128] [Medline: 23343063]

4. Babb S, Malarcher A, Schauer G, Asman K, Jamal A. Quitting Smoking Among Adults - United States, 2000-2015. MMWR Morb Mortal Wkly Rep 2017 Jan 06;65(52):1457-1464. [doi: 10.15585/mmwr.mm6552a1] [Medline: 28056007]

5. Hartmann-Boyce J, Chepkin SC, Ye W, Bullen C, Lancaster T. Nicotine replacement therapy versus control for smoking cessation. Cochrane Database Syst Rev 2018 May 31;5:CD000146 [FREE Full text] [doi: 10.1002/14651858.CD000146.pub5] [Medline: 29852054]

6. Lancaster T, Stead LF. Individual behavioural counselling for smoking cessation. Cochrane Database Syst Rev 2017 Mar 31;3:CD001292 [FREE Full text] [doi: 10.1002/14651858.CD001292.pub3] [Medline: 28361496]

7. Stead LF, Carroll AJ, Lancaster T. Group behaviour therapy programmes for smoking cessation. Cochrane Database Syst Rev 2017 Mar 31;3:CD001007 [FREE Full text] [doi: 10.1002/14651858.CD001007.pub3] [Medline: 28361497]

8. Stead LF, Koilpillai P, Fanshawe TR, Lancaster T. Combined pharmacotherapy and behavioural interventions for smoking cessation. Cochrane Database Syst Rev 2016 Mar 24;3:CD008286. [doi: 10.1002/14651858.CD008286.pub3] [Medline: 27009521]

9. Whittaker R, McRobbie H, Bullen C, Rodgers A, Gu Y, Dobson R. Mobile phone text messaging and app-based interventions for smoking cessation. Cochrane Database Syst Rev 2019 Oct 22;10:CD006611 [FREE Full text] [doi: 10.1002/14651858.CD006611.pub5] [Medline: 31638271]

10. Bricker JB, Watson NL, Mull KE, Sullivan BM, Heffner JL. Efficacy of Smartphone Applications for Smoking Cessation: A Randomized Clinical Trial. JAMA Intern Med 2020 Sep 21;180(11):1-9. [doi: 10.1001/jamainternmed.2020.4055] [Medline: 32955554]

11. Marler JD, Fujii CA, Utley DS, Tesfamariam LJ, Galanko JA, Patrick H. Initial assessment of a comprehensive digital smoking cessation program that incorporates a mobile app, breath sensor, and coaching: cohort study. JMIR Mhealth Uhealth 2019 Feb 04;7(2):e12609 [FREE Full text] [doi: 10.2196/12609] [Medline: 30670372]

12. Beard E, West R. Pilot study of the use of personal carbon monoxide monitoring to achieve radical smoking reduction. $\mathrm{J}$ Smok Cessat 2012 Jul 13;7(1):12-17. [doi: 10.1017/jsc.2012.1]

13. Choi W, Kim C, Lee O. Effects of brief smoking cessation education with expiratory carbon monoxide measurement on level of motivation to quit smoking. Korean J Fam Med 2013 May;34(3):190-198 [FREE Full text] [doi:

10.4082/kjfm.2013.34.3.190] [Medline: 23730486]

14. Risser NL, Belcher DW. Adding spirometry, carbon monoxide, and pulmonary symptom results to smoking cessation counseling: a randomized trial. J Gen Intern Med 1990;5(1):16-22. [doi: 10.1007/BF02602303] [Medline: 2405112]

15. Jamrozik K, Vessey M, Fowler G, Wald N, Parker G, Van Vunakis H. Controlled trial of three different antismoking interventions in general practice. Br Med J (Clin Res Ed) 1984 May 19;288(6429):1499-1503 [FREE Full text] [doi: 10.1136/bmj.288.6429.1499] [Medline: $\underline{6426618}$ ]

16. Fagerström KO. Assessment of the smoker who wants to quit. Monaldi Arch Chest Dis 2001 Apr;56(2):124-127. [Medline: $\underline{11499300]}$

17. Bittoun R. Carbon monoxide meter: the essential clinical tool — the 'stethoscope' — of smoking cessation. J Smok Cessat 2012 Feb 21;3(2):69-70. [doi: 10.1375/jsc.3.2.69]

18. Tobacco Use and Dependence Guideline Panel. Treating Tobacco Use Dependence Update. Agency for Healthcare Research and Quality. Rockville, MD: US Department of Health and Human Services; 2008 May. URL: https://www.ahrq.gov/ prevention/guidelines/tobacco/index.html [accessed 2021-02-06]

19. Coverage for tobacco use cessation treatments. Centers for Disease Control and Prevention. URL: https://www.cdc.gov/ tobacco/quit smoking/cessation/coverage/ [accessed 2020-10-27]

20. Stead LF, Perera R, Bullen C, Mant D, Hartmann-Boyce J, Cahill K, et al. Nicotine replacement therapy for smoking cessation. Cochrane Database Syst Rev 2012 Nov 14;11:CD000146. [doi: 10.1002/14651858.CD000146.pub4] [Medline: 23152200]

21. Final Recommendation Statement - Tobacco Smoking Cessation in Adults, Including Pregnant Women: Behavioral and Pharmacotherapy Interventions. US Preventive Services Task Force. 2018. URL: https://www. uspreventiveservicestaskforce.org/uspstf/document/RecommendationStatementFinal/ tobacco-use-in-adults-and-pregnant-women-counseling-and-interventions [accessed 2020-10-27]

22. Miller W, Rollnick S. Motivational Interviewing: Preparing People For Change Second Edition. New York City: Guilford Press; 2002.

23. Lindson-Hawley N, Thompson TP, Begh R. Motivational interviewing for smoking cessation. Cochrane Database Syst Rev 2015 Mar 02(3):CD006936. [doi: 10.1002/14651858.CD006936.pub3] [Medline: 25726920] 
24. Williams GC, Niemiec CP, Patrick H, Ryan RM, Deci EL. The importance of supporting autonomy and perceived competence in facilitating long-term tobacco abstinence. Ann Behav Med 2009 Jun;37(3):315-324 [FREE Full text] [doi: 10.1007/s12160-009-9090-y] [Medline: 19373517]

25. Abrams D, Niaura R, Brown R, Emmons K, Goldstein M, Monti P. The Tobacco Dependence Treatment Handbook: A Guide To Best Practices. New York City: Guilford Press; 2003.

26. SRNT Subcommittee on Biochemical Verification. Biochemical verification of tobacco use and cessation. Nicotine Tob Res 2002 May;4(2):149-159. [doi: 10.1080/14622200210123581] [Medline: 12028847]

27. Hughes JR, Carpenter MJ, Naud S. Do point prevalence and prolonged abstinence measures produce similar results in smoking cessation studies? A systematic review. Nicotine Tob Res 2010 Jul;12(7):756-762 [FREE Full text] [doi: 10.1093/ntr/ntq078] [Medline: 20504946]

28. Vangeli E, Stapleton J, Smit ES, Borland R, West R. Predictors of attempts to stop smoking and their success in adult general population samples: a systematic review. Addiction 2011 Dec;106(12):2110-2121. [doi: 10.1111/j.1360-0443.2011.03565.x] [Medline: 21752135]

29. Patrick H, Fujii CA, Glaser DB, Utley DS, Marler JD. A comprehensive digital program for smoking cessation: assessing feasibility in a single-group cohort study. JMIR Mhealth Uhealth 2018 Dec 18;6(12):e11708 [FREE Full text] [doi: 10.2196/11708] [Medline: 30563807]

30. Ubhi HK, Michie S, Kotz D, Wong WC, West R. A mobile app to aid smoking cessation: preliminary evaluation of SmokeFree28. J Med Internet Res 2015 Jan 16;17(1):e17 [FREE Full text] [doi: 10.2196/jmir.3479] [Medline: 25596170]

31. Perro J. Mobile apps: what's a good retention rate?. 2018. URL: https://uplandsoftware.com/localytics/resources/blog/ mobile-apps-whats-a-good-retention-rate/ [accessed 2020-12-30]

32. Clement J. Retention rate on day 1 and day 30 of mobile app installs worldwide as of August 2020, by category. Statista. URL: https://www.statista.com/statistics/259329/ios-and-android-app-user-retention-rate/ [accessed 2020-12-30]

33. Bricker JB, Copeland W, Mull KE, Zeng EY, Watson NL, Akioka KJ, et al. Single-arm trial of the second version of an acceptance \& commitment therapy smartphone application for smoking cessation. Drug Alcohol Depend 2017 Jan 01;170:37-42 [FREE Full text] [doi: 10.1016/j.drugalcdep.2016.10.029] [Medline: 27870987]

34. Iacoviello BM, Steinerman JR, Klein DB, Silver TL, Berger AG, Luo SX, et al. Clickotine, a personalized smartphone app for smoking cessation: initial evaluation. JMIR Mhealth Uhealth 2017 Apr 25;5(4):e56 [FREE Full text] [doi: 10.2196/mhealth.7226] [Medline: 28442453]

35. Webb J, Peerbux S, Smittenaar P, Siddiqui S, Sherwani Y, Ahmed M, et al. Preliminary outcomes of a digital therapeutic intervention for smoking cessation in adult smokers: randomized controlled trial. JMIR Ment Health 2020 Oct 06;7(10):e22833 [FREE Full text] [doi: 10.2196/22833] [Medline: 33021488]

36. Krishnan N, Elf JL, Chon S, Golub JE. COach2Quit: a pilot randomized controlled trial of a personal carbon monoxide monitor for smoking cessation. Nicotine Tob Res 2019 Oct 26;21(11):1573-1577 [FREE Full text] [doi: 10.1093/ntr/nty182] [Medline: 30169740]

37. Garrison KA, Pal P, O'Malley SS, Pittman BP, Gueorguieva R, Rojiani R, et al. Craving to Quit: a randomized controlled trial of smartphone app-based mindfulness training for smoking cessation. Nicotine Tob Res 2020 Mar 16;22(3):324-331 [FREE Full text] [doi: 10.1093/ntr/nty126] [Medline: 29917096]

38. Alessi SM, Rash CJ, Petry NM. A randomized trial of adjunct mHealth abstinence reinforcement with transdermal nicotine and counseling for smoking cessation. Nicotine Tob Res 2017 Mar 01;19(3):290-298 [FREE Full text] [doi: 10.1093/ntr/ntw155] [Medline: 27613901]

39. Masaki K, Tateno H, Nomura A, Muto T, Suzuki S, Satake K, et al. A randomized controlled trial of a smoking cessation smartphone application with a carbon monoxide checker. NPJ Digit Med 2020;3:35. [doi: 10.1038/s41746-020-0243-5] [Medline: 32195370]

40. Baskerville NB, Struik LL, Guindon GE, Norman CD, Whittaker R, Burns C, et al. Effect of a mobile phone intervention on quitting smoking in a young adult population of smokers: randomized controlled trial. JMIR Mhealth Uhealth 2018 Oct 23;6(10):e10893 [FREE Full text] [doi: 10.2196/10893] [Medline: 30355563]

41. Danaher BG, Tyler MS, Crowley RC, Brendryen H, Seeley JR. Outcomes and device usage for fully automated internet interventions designed for a smartphone or personal computer: The MobileQuit smoking cessation randomized controlled trial. J Med Internet Res 2019 Jun 06;21(6):e13290 [FREE Full text] [doi: 10.2196/13290] [Medline: 31172967]

42. BinDhim NF, McGeechan K, Trevena L. Smartphone Smoking Cessation Application (SSC App) trial: a multicountry double-blind automated randomised controlled trial of a smoking cessation decision-aid 'app'. BMJ Open 2018 Jan 21;8(1):e017105 [FREE Full text] [doi: 10.1136/bmjopen-2017-017105] [Medline: 29358418]

43. Matkin W, Ordóñez-Mena JM, Hartmann-Boyce J. Telephone counselling for smoking cessation. Cochrane Database Syst Rev 2019 May 02;5:CD002850 [FREE Full text] [doi: 10.1002/14651858.CD002850.pub4] [Medline: 31045250]

44. Hughes JR, Keely J, Naud S. Shape of the relapse curve and long-term abstinence among untreated smokers. Addiction 2004 Jan;99(1):29-38. [doi: 10.1111/j.1360-0443.2004.00540.x] [Medline: 14678060]

45. Zhou X, Nonnemaker J, Sherrill B, Gilsenan AW, Coste F, West R. Attempts to quit smoking and relapse: factors associated with success or failure from the ATTEMPT cohort study. Addict Behav 2009 Apr;34(4):365-373. [doi:

$\underline{\text { 10.1016/j.addbeh.2008.11.013] [Medline: 19097706] }}$ 
46. Herd N, Borland R, Hyland A. Predictors of smoking relapse by duration of abstinence: findings from the International Tobacco Control (ITC) Four Country Survey. Addiction 2009 Dec;104(12):2088-2099 [FREE Full text] [doi: 10.1111/j.1360-0443.2009.02732.x] [Medline: 19922574$]$

47. Smit ES, Hoving C, Schelleman-Offermans K, West R, de Vries H. Predictors of successful and unsuccessful quit attempts among smokers motivated to quit. Addict Behav 2014 Sep;39(9):1318-1324. [doi: 10.1016/j.addbeh.2014.04.017] [Medline: 24837754]

48. Hymowitz N, Cummings KM, Hyland A, Lynn WR, Pechacek TF, Hartwell TD. Predictors of smoking cessation in a cohort of adult smokers followed for five years. Tob Control 1997;6(Suppl 2):S57-S62 [FREE Full text] [doi: 10.1136/tc.6.suppl 2.s57] [Medline: 9583654]

49. Stolz D, Scherr A, Seiffert B, Kuster M, Meyer A, Fagerström KO, et al. Predictors of success for smoking cessation at the workplace: a longitudinal study. Respiration 2014;87(1):18-25 [FREE Full text] [doi: 10.1159/000346646] [Medline: 23594795]

50. Kale D, Gilbert HM, Sutton S. Are predictors of making a quit attempt the same as predictors of 3-month abstinence from smoking? Findings from a sample of smokers recruited for a study of computer-tailored smoking cessation advice in primary care. Addiction 2015 Oct;110(10):1653-1664. [doi: 10.1111/add.12972] [Medline: 25939254]

51. Reid JL, Hammond D, Boudreau C, Fong GT, Siahpush M, ITC Collaboration. Socioeconomic disparities in quit intentions, quit attempts, and smoking abstinence among smokers in four western countries: findings from the International Tobacco Control Four Country Survey. Nicotine Tob Res 2010 Oct;12(Suppl 1):S20-S33 [FREE Full text] [doi: 10.1093/ntr/ntq051] [Medline: 20889477]

52. Ubhi HK, Kotz D, Michie S, van Schayck OCP, West R. A comparison of the characteristics of iOS and Android users of a smoking cessation app. Transl Behav Med 2017 Jun;7(2):166-171 [FREE Full text] [doi: 10.1007/s13142-016-0455-z] [Medline: 28168609]

53. Benowitz NL, Bernert JT, Foulds J, Hecht SS, Jacob P, Jarvis MJ, et al. Biochemical verification of tobacco use and abstinence: 2019 update. Nicotine Tob Res 2020 Jun 12;22(7):1086-1097. [doi: 10.1093/ntr/ntz132] [Medline: 31570931]

54. Connor Gorber S, Schofield-Hurwitz S, Hardt J, Levasseur G, Tremblay M. The accuracy of self-reported smoking: a systematic review of the relationship between self-reported and cotinine-assessed smoking status. Nicotine Tob Res 2009 Jan;11(1):12-24. [doi: 10.1093/ntr/ntn010] [Medline: 19246437]

\author{
Abbreviations \\ CASC: CureApp Smoking Cessation \\ CO: carbon monoxide \\ CPD: cigarettes per day \\ FDA: Food and Drug Administration \\ IRB: Institutional Review Board \\ ITT: intention to treat \\ NRT: nicotine replacement therapy \\ OR: odds ratio \\ PPA: point prevalence abstinence \\ RCT: randomized controlled trial \\ RR: relative risk \\ USCPG: United States Clinical Practice Guideline
}

Edited by G Eysenbach; submitted 06.11.20; peer-reviewed by K Masaki, J Heffner, J Steinerman, M Bardus; comments to author
$27.11 .20 ;$ revised version received 11.01.21; accepted 21.01.21; published 15.02.21
Please cite as:
Marler JD, Fujii CA, Galanko JA, Balbierz DJ, Utley DS
Durability of Abstinence After Completing a Comprehensive Digital Smoking Cessation Program Incorporating a Mobile App, Breath
Sensor, and Coaching: Cohort Study
J Med Internet Res 2021;23(2):e25578
URL: $\underline{\text { http://www.jmir.org/2021/2/e25578/ }}$
doi: $\underline{10.2196 / 25578}$
PMID: $\underline{33482628}$

CJennifer D Marler, Craig A Fujii, Joseph A Galanko, Daniel J Balbierz, David S Utley. Originally published in the Journal of Medical Internet Research (http://www.jmir.org), 15.02.2021. This is an open-access article distributed under the terms of the 
Creative Commons Attribution License (https://creativecommons.org/licenses/by/4.0/), which permits unrestricted use, distribution, and reproduction in any medium, provided the original work, first published in the Journal of Medical Internet Research, is properly cited. The complete bibliographic information, a link to the original publication on http://www.jmir.org/, as well as this copyright and license information must be included. 